ББК 63.4

\author{
Организация конференциии и издание материалов проведень \\ при финансовой поддержке Российского фонда фундаментальных исследований, \\ проект № 19-09-20008
}

Утверждено к печати Ученым советом ИИМК РАН

Редакционная коллегия тома I: В. А. Алёкшин, Л. Б. Кирчо (отв. редакторы),

В. П. Никоноров, В. Я. Стёганцева; В. В. Терёхина

Рецензенты: д. и. н. Л. Б. Вишняцкий, д. и. н. А. А. Выборнов

Программный комитет конференции: академик РАН, д. и. н., проф. М. Б. Пиотровский

(Государственный Эрмитаж, почетный председатель); д. и. н. В. А. Лапшин (ИИМК РАН, председатель); д. и. н. А. В. Головнёв (МАЭ РАН, сопредседатель); д. и. н. В. А. Дергачёв (Высшая антропологическая школа, Молдова, сопредседатель); д. и. н. И. Ф. Попова (ИВР РАН, сопредседатель); академик АН Республики Узбекистан, д. и. н., проф. Э. В. Ртвеладзе (сопредседатель); к. и. н. А. В. Поляков (ИИМК РАН, зам. председателя); к. и. н. В. А. Алёкшин (ИИМК РАН, зам. председателя); д. и. н. Ю. Е. Берёзкин (МАЭ РАН); Dr., Prof. Н. Бороффка (Германский археологический институт, Германия); В. С. Бочкарёв (ИИМК РАН); Dr. Э. Кайзер (Свободный университет Берлина, Германия); к. и. н. М. Т. Кашуба (ИИМК РАН); д. и. н. Л. Б. Кирчо (ИИМК РАН); к. и. н. А. В. Кияшко (Южный федеральный университет); к. и. н. П. Ф. Кузнецов (СГСПУ);

к. и. н. Н. М. Малов (СНИГУ); к. и. н. В. П. Никоноров (ИИМК РАН); Ю. Ю. Пиотровский

(Государственный Эрмитаж); д. и. н., проф. Д. Г. Савинов (Институт истории СПбГУ);

к. и. н. В. Н. Седых (Институт истории СПбГУ); к. и. н. Н. Н. Скакун (ИИМК РАН);

к. и. н. Н. Ф. Соловьёва (ИИМК РАН); к. и. н. А. И. Торгоев (Государственный Эрмитаж); к. и. н. Е. А. Черлёнок (Институт истории СПбГУ)

Организационный комитет конференции: к. и. н. А. В. Поляков (ИИМК РАН, председатель);

к. и. н. В. А. Алёкшин (ИИМК РАН, зам. председателя); В. С. Бочкарёв (ИИМК РАН); ); к. и. н. М. Т. Кашуба (ИИМК РАН); д. и. н. Л. Б. Кирчо (ИИМК РАН);

А. И. Климушина (ИИМК РАН, отв. секретарь); к. и. н. В. П. Никоноров (ИИМК РАН); Ю. Ю. Пиотровский (Государственный Эрмитаж); В. Я. Стёганцева (ИИМК РАН); В. В. Терёхина

(ИИМК РАН, МАЭ РАН, отв. секретарь); к. и. н. Е. С. Ткач (ИИМК РАН); И. Ж. Тутаева (Государственный Эрмитаж); к. и. н. Е. А. Черлёнок (Институт истории СПбГУ)

Древности Восточной Европы, Центральной Азии и Южной Сибири в контексте связей и взаимодействий в евразийском культурном пространстве (новые данные и концепции): Материалы Международной конференции, 18-22 ноября 2019 г., Санкт-Петербург. Т. I. Древняя Центральная Азия в контексте евразийского культурного пространства (новые данные и концепции). К 90-летию со дня рождения патриарха евразийской археологии Вадима Михайловича Массона. - СПб.: ИИМК РАН, Невская Типография, 2019. — 291 с.

ISBN 978-5-907053-34-2

DOI 10.31600/978-5-907053-34-2 
с разных территорий памятника, из разных типов погребальных сооружений, а также из разных стратиграфических слоев.

Предполагается продолжение работы с серией гонурских зеркал в Национальном музее и Музее изобразительных искусств Туркменистана (г. Ашхабад). Таким образом, полученные Н. Н. Тереховой и С. Краусом данные могут быть существенно уточнены и детализированы нашими исследованиями. Запланирована подготовка каталога зеркал.

\title{
Литература
}

Сарианиди В. И. 2001. Некрополь Гонура и иранское язычество. М.

Терехова Н. Н. 1990. Обработка металлов в древней Маргиане // Сарианиди В. И. Древности страны Маргуш. Ашхабад. С. 177-202.

Тишкин А. А., Серегин Н. Н. 2011. Металлические зеркала как источник по древней и средневековой истории Алтая (по материалам Музея археологии и этнографии Алтая Алтайского государственного университета). Барнаул.

Kraus S. 2016. Metallurgical Investigations in Gonur Depe, Turkmenistan // Дубова Н. А. (ред.). Тр. МарАЭ. Т. 6: Памяти В. И. Сарианиди. М. С. 257-265.

Sarianidi V. 2007. Necropolis of Gonur. Athens.

\section{THE X-RAY FLUORESCENCE ANALYSIS OF METAL MIRRORS FROM THE ARCHAEOLOGICAL COMPLEX OF GONUR DEPE (TURKMENISTAN)}

\author{
Alexei A. Tishkin ${ }^{\star}$, Nadezhda A. Dubova ${ }^{* *}$, Nikolai N. Seryogin ${ }^{\star}$ \\ ${ }^{\star}$ Altai State University, Barnaul, Russia; ${ }^{* *}$ Institute of Ethnology and Anthropology of the Russian \\ Academy of Sciences, Moscow, Russia
}

Keywords: Turkmenistan, Gonur Depe, metal mirrors, X-ray fluorescence analysis.

In the course of the excavations at the widely known archaeological complex of Gonur Depe in Turkmenistan, a representative collection of early metal mirrors was discovered. Most of them are currently stored in the Mary Regional Museum of Local History. Some products have been restored and are now on display. In 2018, the most important artifacts were investigated using a portable Xray fluorescence spectrometer. During this work, a tested algorithm for studying the mirrors made of non-ferrous metals was realized. As a result, the information about various copper-based alloys was obtained. In addition, for a comparative analysis similar objects that were found on two other simultaneous monuments were studied by the spectrometer. The paper presents the element-wise indicators got by testing the eight metal mirrors. All the results fixed require more detailed understanding. The preparation of a catalogue of the mirrors is planned.

\section{МЕТАЛЛИЧЕСКИЕ “СТЕРЖНИ" И ИХ НАЗНАЧЕНИЕ (ПО ДАННЫМ АРХЕОЛОГИЧЕСКИХ ПАМЯТНИКОВ ЦЕНТРАЛЬНОЙ АЗИИ ІV-ІІ ТЫС. ДО Н. Э.)}

\author{
Ф. А. Раззоков \\ Российско-Таджикский университет, Душанбе, Таджикистан
}

DOI: 10.31600/978-5-907053-34-2-86-88

Ключевые слова: археология, Центральная Азия, эпоха полеометалла (IV-II тыс. до н.э.), погребальные комплексы, металлические стержни.

Эпоха паллеометалла является временем значимых перемен в древних культурах. Археологи более 100 лет исследуют эту пору по многочисленным памятникам Древнего 
Востока. Основной материал, дающий возможность реконструировать культурные процессы данного времени, представлен открытыми и закрытыми археологическими комплексами, обнаруженными при раскопках поселений и могил. Системное изучение происходящих из этих комплексов артефактов позволяет археологам воссоздавать процессы развития отдельных обществ в конкретных географических условиях. По результатам этих исследований выяснилось, что Центральная Азия в эпоху полеометалла являлась одним из очагов развития древнеземледельческого хозяйства Старого Света. Этот период времени (V-II тыс. дон.э.), включающий энеолит, ранний, средний и поздний бронзовый век, характеризуется становлением и развитием древнеземледельческой культуры в Центральной Азии, когда формируются основные черты культурного каркаса местной цивилизации.

В настоящей работе рассматривается вопрос о назначении так называемых металлических «стержней» из памятников эпохи палеометалла Центральной Азии. Эти находки является частью сопроводительного инвентаря погребальных комплексов, в которых они встречаются совместно с керамическими сосудами, оружием, зеркалами, украшениями из драгоценных металлов и полудрагоценных камней, пряслицами, печатями, браслетами и прочими изделиями ремесленного производства. Однако металлические «стержни» реже по сравнению с другими артефактами помещали в могилы, хотя по совокупности находок в синхронных памятниках Центральной Азии к настоящему времени известна значительная коллекция таких «стержней» Очевидно, данные предметы имели важное значение в жизни первых земледельцев, но их назначение до сих пор однозначно не выяснено.

В литературе говорится о «стержнях» как о предметах туалета и украшениях: жезлы, эмблемы, булавки (Сарианиди 1965: 40, рис. 11, 5; 17-20; 1977: табл. II, 5; табл. III, 2; рис. $42-$ 44; Кузьмина 1966: 76), косметический стержень, металлический стержень, косметические лопаточки (Кирчо 1990; 2005; 2018), инструменты для веретена (Хлопин 1983: 22, рис. 7, 1).

Исследователи обращали внимания, прежде всего, на типологию этих изделий, нежели на их функциональное значение. Это вызвано спецификой типологического метода в археологии, когда внешние признаки и материал предмета служат основными критериями типологического анализа. В совокупности с другими данными возможно установить основное назначение «стержней», область распространения которых охватывает не только ареал анауской культуры (территории современных Южного Туркменистана, Узбекистана, Таджикистана), но и области распространения древнеземледельческих культур в Северном и Южном Афганистане (Мундигак, Саид-кала и другие), Индо-Иранском пограничье (Шахри Сохте).

\section{Литература}

Кузьмина Е. Е. 1966. Металлические изделия энеолита и бронзового века в Средней Азии. М.

Сарианиди В. И. 1965. Энеолит южных областей Средней Азии. Ч. 4: Памятники позднего энеолита Юго-Восточной Туркмении. М. (САИ. Вып. Б3-8).

Сарианиди В. И. 1977. Древние земледельцы Афганистана. М.

Хлопин И. Н. 1983. Юго-Западная Туркмения в эпоху поздней бронзы. Л.

Кирчо Л. Б. 1990. Древнейшие печати и их оттиски из Алтын-депе // СА. № 3. С. 176-183.

Кирчо Л. Б. 2005. Погребальный инвентарь Алтын-депе // Кирчо Л. Б., Алёкшин В. А. Хронология эпохи позднего энеолита - средней бронзы Средней Азии (погребения Алтындепе). СПб. С. 347-421 (Тр. ИИМК РАН. Т. 16).

Кирчо Л. Б. 2018. О функции так называемых каменных светильников на юге Средней Азии и Среднем Востоке // ЗИИМК. № 18. С. 20-27. 


\title{
METAL “RODS” AND THEIR PURPOSE \\ (ACCORDING TO DATA FROM ARCHAEOLOGICAL SITES \\ OF CENTRAL ASIA OF THE $4^{\mathrm{TH}}-2^{\mathrm{ND}}$ MILLENNIA BC)
}

Farhod A. Razzoqov

Russian-Tadjik University, Dushanbe, Tajikistan

Keywords: archaeology, Central Asia, Paleometal Age (4th-2nd mil. BC), grave complex, metal "rod", tool assignment issues.

Thanks to the study of ancient agricultural monuments of Central Asia, many, but not all, features of the development of the culture of local communities were clarified. Currently, scholars are trying to give a new interpretation to a number of products of material culture (in this case, metal "rods") compared with their predecessors.

\section{ПАРНЫЕ НЕОДНОВРЕМЕННЫЕ ПОГРЕБЕНИЯ ЮЖНОГО УРАЛА И СРЕДНЕЙ АЗИИ: СРАВНИТЕЛЬНАЯ ХАРАКТЕРИСТИКА ${ }^{1}$}

\author{
Я. В. Рафикова \\ Институт истории, языка и литературы Уфимского федерального исследовательско- \\ го иентра РАН, Уфа, Россия
}

DOI: $10.31600 / 978-5-907053-34-2-88-91$

Ключевые слова: неодновременные парные погребения, алакульская культура, тазабагъябская культура, бишкентско-вахшская культура.

Неодновременные парные разнополые погребения, где покойники уложены «лицом друг к другу», исследованы в могильниках эпохи поздней бронзы Южного Урала (алакульская) и Средней Азии (тазабагъябская и бишкентско-вахшская культуры). В этих культуpax количество упомянутых захоронений относительно сопоставимо: в алакульских - 10, в тазабагъябских - 7, в бишкентско-вахшских - 6 (Рафикова 2018; Итина 1961; Виноградов и др. 1986; Мандельштам 1962; Пьянкова 1987).

Рассматриваемые погребения можно разделить на три варианта в зависимости от состояния останков ранее захороненного индивида: в сочлененном состоянии и полном порядке (вариант 1); частично нарушены (вариант 2); полностью нарушены и представляют собой груду костей (вариант 3) (Рафикова 2018: 53).

Погребения варианта 1 представлены только в алакульской и бишкентско-вахшской культурах. В единственном алакульском погребении (Ново-Аккермановка 4) подхороненная женщина лежит на груди, лицом вниз, с повернутыми вправо ногами, ранее захороненный мужчина располагался скорченно, на левом боку (рис. 1, 1). В бишкентско-вахшских погребениях (Ранний Тулхар, мог. 20; Ой Куль, мог. 6) тело подхороненного покойника уложено в могилу над останками ранее погребенного усопшего, практически полностью перекрывая их (рис. 1,2). В этих погребениях мужчины лежали на правом боку, а женщины на левом. И в алакульском, и в бишкентско-вахшских захоронениях первыми похоронены мужчины.

\footnotetext{
${ }^{1}$ Работа выполнена в рамках подпрограммы «Памятники материальной и духовной культуры в современной информационной среде» (I.25) проект № 255 «Парные разнополые погребения эпохи бронзы от Урала до Индостана как источник по реконструкции семейно-брачной и социальной структуры» программы Президиума РАН «Социально-гуманитарные аспекты устойчивого развития и обеспечения стратегического прорыва России» и государственного задания ИИЯЛ УФИЦ PAН на 2019 г.
} 